\title{
After-school time use of urban adolescents: Effects on achievement, problem behaviors, and happiness
}

\author{
Paula Cristina Martins ${ }^{\mathrm{a}}$ (D) , Vitor Hugo Oliveira $^{\mathrm{a}}$ (D) Sílvia Maria Mendes ${ }^{\mathrm{a}}$ (D), and \\ Gloria Fernández-Pacheco ${ }^{\mathrm{b}}$

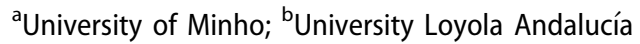

\begin{abstract}
Leisure is a context for both risk and protection of adolescent wellbeing. Using a person-centered analysis, the present study examined the links between after-school time use and the adjustment of an urban sample of 7 th-12th graders $(n=3,808)$, who self-reported on their leisure activities, school achievement, problem behaviors, and happiness. Results indicated that time use patterns were distributed in five clusters: Creative/Social, Productive/Home, High-Social/Sports, Uninvolved/Sports, and Uninvolved/Home. These patterns of time use varied by age, gender and SES, and were linked with adolescent outcomes in a way that adolescents involved with multiple constructive activities presented better adjustment compared with their either uninvolved or socially oriented counterparts. Specific groups of adolescents were at higher risk for problem behaviors linked to after-school time use. These findings have relevant implications for evidence-based interventions and policies aiming at promoting adolescent well-being and targeting at-risk populations of youth.
\end{abstract}

\section{KEYWORDS}

Health; leisure activities; person-centered analysis; psychosocial adjustment; youth

After-school time use has been associated with several dimensions of adolescent health and development as activities provide different experiences and resources that influence adolescent functioning (Agans et al., 2014; Feldman \& Matjasko, 2005; Lam \& McHale, 2015; Larson \& Verma, 1999). Leisure as a social institution associated with adolescence is, therefore, a context for both risk and protection (Caldwell \& Smith, 2006). A constructive involvement with after-school activities is facilitative of several aspects of adolescent well-being. Engaging with those activities often means the provision of opportunities to learn valued skills, to form social bonds, and develop a sense of selfefficacy as well as a positive identity (Eccles et al., 2003; Feldman \& Matjasko, 2005). In addition, structured activities may provide developmental experiences characterized by the presence of supportive adults and socially competent peers in a goal oriented and challenging context (Mahoney \& Stattin, 2000; Trainor, et al., 2010). Conversely, unstructured leisure activities may be a potential context for deviancy and risk behaviors (Caldwell \& Smith, 2006). An overall low participation or the engagement with activities lacking structure, supervision, and positive social norms have been linked to problem behaviors (Barnes et al., 2007; Mahoney \& Stattin, 2000; Wolf et al., 2015), lower school 
achievement (Badura et al., 2016), and lower levels of psychological well-being (Badura et al., 2015; Bartko \& Eccles, 2003). The main goals of the present study are to examine differences on adolescent after-school time use patterns and to investigate how these different patterns are associated with adolescent adjustment.

\section{Age, gender and socioeconomic differences in adolescent time use}

Age, gender, and socioeconomic status (SES) are important variables in time use studies because they are associated with changes in leisure time (Farb \& Matjasko, 2012). Participation in school-based activities, organized sports and physical activity have been reported to decline during adolescence (Inchley et al., 2016; Pedersen, 2005), whilst an increase in time with peers in social activities has been observed (Currie et al., 2012).

In relation to gender differences, boys spend more time in physical activities, going out with friends and on screen-time leisure. Conversely, girls spend more time in personal care, household chores, socializing with family, shopping, reading, and on academic pursuits (Barnes et al., 2007; Currie et al., 2012; Hunt et al., 2014; Olds et al., 2009; Pedersen, 2005; Trainor et al., 2010; Wolf et al., 2015). Because of gender disparities in activity involvement, boys are consistently represented in higher proportion in the sports, social leisure, and low-involvement patterns of time use (non-participation, disengaged) whilst girls are represented in the school-oriented and high-involvement patterns (engaged in multiple activities) (Bartko \& Eccles, 2003; Feldman \& Matjasko, 2007; Linver et al., 2009; Shanahan \& Flaherty, 2001; Wolf et al., 2015). The present study aims at contributing to the understanding of how these gendered differences in activity patterns may be associated with possible gendered differences in adolescent adjustment.

Regarding SES, higher family affluence is linked to more physical activity, meals with parents, going out in the evening, and time spent with friends (Currie et al., 2012; Inchley et al., 2016). Youth from affluent families are more likely to be involved in multiple activities, with a higher focus on academic activities, while lower SES is associated with patterns of time use characterized by low-involvement, low physical activity, and higher screen-time (Bartko \& Eccles, 2003; Ferrar et al., 2013; Linver et al., 2009; Pedersen, 2005).

\section{After-school time use and adolescent adjustment}

The academic achievement of adolescents is linked to their leisure time and participation in after-school activities. Studies have reported that the breadth of activities as well participation in high-school clubs and sports, are positively associated with achievement (Fredricks \& Eccles, 2006; Fredricks \& Eccles, 2010). Higher levels of participation in extracurricular and organized leisure activities has also been associated with higher academic motivation and goals (Darling, 2005; Wolf et al., 2015), better school achievement, as well as lower levels of school-related stress, regardless of gender and age (Badura et al., 2016; Himelfarb et al., 2014). Notably, Covay and Carbonaro (2010) found that the influence of extracurricular participation on cognitive and non-cognitive skills varied by SES. Conversely, involvement in unstructured activities can be 
associated with lower intrinsic motivation and poorer academic performance (Wolf et al., 2015).

Prior research has also found strong relationships between after-school time use and both problematic and adaptive behavior in adolescence. Patterns characterized by a higher engagement with multiple activities are positively linked to a lower number of risk behaviors such as substance use, sexual activity, delinquency, and aggression, as well as lower internalizing and externalizing symptoms (Agans et al., 2014; Fredricks \& Eccles, 2010; Rose-Krasnor et al., 2006). In addition, adolescents engaged in structured time use and prosocial activities show a more positive psychosocial functioning and civic engagement (Bartko \& Eccles, 2003; Darling, 2005; Fredricks \& Eccles, 2006; Giorgi, 2014; Mancini \& Huebner, 2004; Metzger et al., 2009). Conversely, involvement in unstructured leisure activities is linked to higher rates of problem behaviors (Giorgi, 2014; Wolf et al., 2015) and a relationship has been established between highly social and unsupervised activities, such as going to clubs and parties, and substance use (Trainor et al., 2010). In addition, family time and shared meals represent a protective factor against the development of behavioral problems, while unsupervised time with peers is predictive of substance use and delinquent behavior (Barnes et al., 2007; Levin et al., 2012).

The relationship between after-school time use and adolescents' happiness and psychological well-being has received less attention from researchers. Nevertheless, the breadth of participation in activities has been positively associated with indicators of adolescent adjustment (Fredricks \& Eccles, 2006). Participation in organized leisure activities has been associated with higher life satisfaction regardless of gender and age (Badura et al., 2015), while engagement in less structured and less challenging leisure activities is linked to overall poorer psychological well-being, including lower self-esteem, life satisfaction, negative mood, and depressive symptoms (Agans et al., 2014; Trainor et al., 2010). As before mentioned, the breadth of activity involvement benefits adolescents' psychological well-being and social functioning, and compensatory and additive effects of different activities and experiences have been reported (Rose-Krasnor et al., 2006). However, Fredricks and Eccles (2008) found, for example, that 8th graders participating in school sports teams had a decrease in depressive symptoms, but this was only observed for those from higher SES households. The role of SES in the relationship between activity participation and developmental outcomes is still underexplored (Fredricks \& Eccles, 2008), and in a review, Farb and Matjasko (2012) called for further investigation of this variable.

\section{Present study}

After-school activities and adolescent adjustment go beyond linear, unidimensional relationships. Both positive and negative outcomes for adolescents are associated with different multidimensional patterns of participation, as young people navigate through multiple activities embedded in the social and cultural settings of everyday life. Different combinations of everyday activities and experiences, associated with co-occurring behaviors, may predict adolescent functioning in a way that single isolated activities 
and individual behaviors cannot (Ferrar et al., 2013). Instead of a focus on single categories (e.g., sports, extracurricular), there is a growing recognition of the need to study adolescents' daily activities as interconnected, complementing elements that are organized around durable patterns. Person-centered research effectively portrays this complexity, understanding the person as an organized whole rather than a summation of variables, and considering the broader arrangements of everyday activity participation (Hunt \& McKay, 2015).

Several studies have reported that adolescents concurrently involved in multiple structured or productive activities (e.g., youth organizations, sports, extracurricular, academic) present better adjustment than their single-activity peers (participation in only one category) and those who are simply uninvolved and disengaged (Feldman \& Matjasko, 2007; Ferrar et al., 2013; Linver et al., 2009; Metzger et al., 2009). A diverse portfolio of activities that provides complementing growth experiences is consistently associated with positive youth development, the optimal adjustment of adolescents, and fewer problem behaviors (Agans et al., 2014; Linver et al., 2009). Researchers need to distinguish the time use patterns that are protective from those that pose a risk to adolescent well-being, adding to previous research essentially based on the effects of single activities (e.g., sports, homework) or the total number of organized activities (e.g., breadth). Therefore, the present study provides a broader perspective on adolescent leisure by analyzing activities that naturally occur in different settings (home, neighborhood, community) and that are diverse in its characteristics (individual vs. social; structured vs. unstructured), thus providing a richer description of adolescent leisure. In the present study activities include, for example, family meals, socializing with peers, sports, creative pursuits, evenings out, and studying at home.

Despite the increasing interest in the developmental opportunities of time use in adolescence, observable by the amount and diversity of literature produced in the field, studies in the European context that employ a nuanced examination of afterschool time use and adolescent well-being are lacking. In addition, this study adds to the literature, predominantly based on the participation in discrete activities or breadth of participation, by analyzing leisure activity patterns as multidimensional units, which more clearly describe adolescent time use. In addition, despite consistent reports of age and gender differences in after-school time use, SES differences are less apparent and mixed or limited results have been reported (Farb \& Matjasko, 2012; Hunt et al., 2014). Most importantly, the identification of both risk and protective patterns of after-school leisure and subgroup variations in time use could enable effective evidence-based interventions and policies aimed at enhancing adolescent health and well-being.

In sum, this study aimed at examining the after-school time use of adolescents and its links with adjustment. The research questions are the following: (1) Does the way adolescents spend their after-school leisure time, in terms of both discrete categories of activities and patterns of time use, vary according to age, gender, and SES?; (2) Are these after-school patterns of time use associated with adolescent adjustment?; and, (3) Do these associations between patterns of time use and adolescent adjustment vary according to age, gender, and SES? 


\section{Methods}

\section{Participants}

Data was collected from a Portuguese city-based stratified random sample of the International Self-Report Delinquency study (ISRD-3), an ongoing international, school-based survey on juvenile delinquency, victimization, and social behavior. This collaborative international project aims at comparing differences and trends in offending and victimization, exploring theoretical issues related to delinquency, and informing policy. A random sample of schools stratified by city (Lisbon, Porto, Braga), school type (public, private), and grade (7th-12th) was drawn from a complete list provided by the Ministry of Education. A total of 159 schools agreed to participate, resulting in 4,124 students surveyed, 4,048 of which with valid/complete questionnaires. Response rate at student level was $76 \%$ for 7 th-9th graders and $79 \%$ for 10th-12th graders. The age limit for this study was established at 18 years thus excluding older students from the analyses (240 students between 19 and 21 years). Therefore, the present study utilized data from a sample of 3,808 Portuguese adolescents (54\% girls), 7 th-12th graders, aged $12-18$ years $(M=15.01, S D=1.86)$. Most participants were living in a nuclear household (71\%). A total of $21 \%$ reported a migrant origin (at least one parent was born in another country) and $15 \%$ a minority status (self-reported). A total of $79 \%$ of mothers and $83 \%$ of fathers were employed and $9 \%$ of families were welfare recipients.

\section{Procedures}

Parents and students received information and a consent/assent form using an opt-in procedure. Students completed a paper-and-pencil or online version of the ISRD-3 Questionnaire (Marshall et al., 2013) in classrooms during the scheduled class time under the supervision of a research team member. Participation was anonymous and voluntary as explained to students prior to data collection. The study received the approval of the University Research Ethics Committee, the National Agency for Data Protection, the Ministry of Education, and School Boards.

\section{Measures}

The ISRD-3 Questionnaire has been developed as a result of many years of experience with the ISRD-1 (considered the pilot study) and the ISRD-2 (full implementation of the design). Based on pilot studies and extensive consultation and discussion, improvements have been implemented in this version to deal with previous problems and make it a reliable assessment tool. It consists of 11 modules which assess several domains such as leisure and peers, school, substance use, delinquency or victimization, encompassing items that directly address theoretical questions (some of them emergent) and that are based as much as possible on validated scales (see Marshall et al., 2013). 


\section{After-school time use}

Respondents were asked the type and frequency of activities they were usually engaged with ("What kind of things do you usually do in your free time?"). The activity categories were sports (sports and physical exercise), study (studying, homework), creative (theater, music, drawing, writing, or reading), social 1 (hanging out in cafes, bars or concerts), and social 2 (hanging out in shopping centers, streets, parks, and/or neighborhood). Response options were never (0), sometimes (1), and frequently (2). In addition, adolescents reported the weekly frequency of shared family meals (from never to daily), and evenings out ("How many times you go out at night"; from never to daily) using 8point scales (Marshall et al., 2013). For the Chi-square tests specifically, and considering the frequency distribution, both the family meals (never to five times per week =1; six times to seven times per week $=2$ ) and evenings out (never to one night per week =1; two times per week to daily $=2$ ) variables were dichotomized, representing different levels of youth involvement in the activities.

\section{Leisure time companionship}

The companionship question assessed with whom adolescents usually spent their leisure time (alone $=1$, with family $=2$, with friends $=3$ ). This variable was exclusively used for the cluster-solution validation (see Clatworthy et al., 2005; Metzger et al., 2009).

\section{Perceived school achievement}

Achievement was assessed by the question "How are your grades at school?" using a 7-point scale (from weak to excellent) (Marshall et al., 2013). Considering the frequency distribution, the variable was dichotomized (weak to average $=0$; above average to excellent $=1$ ) representing two significantly distinct levels of perceived academic competence. Achievement is correlated with health-behaviors and school satisfaction (Kristjánsson et al., 2009) and it is a good indicator of present attainment on developmental tasks that have future implications (Witkow, 2009), thus being included as an indicator of adjustment.

\section{Problem behaviors}

Offending was assessed using the number of offenses reported during the previous year. Participants could answer yes or no to 14 items asking them about specific offenses (e.g., vandalism, shoplifting, burglary, extortion, assault, drug dealing). Participants also self-reported on past-month binge drinking and cannabis smoking episodes ("In the last 30 days, how many times have you drank five or more drinks in a row?"; "Have you ever used cannabis? If yes, how many times in the last 30 days?") (Marshall et al., 2013). Binary indicators of any number of offenses compared to no offenses and substance use compared with no substance use in the past year/month were computed for the three behaviors, being therefore included as indicators of behavioral health (DuRant et al., 1999; Loeber et al., 1999). 


\section{Happiness}

Happiness was measured by the item: "Think about the last six months. Have you been happy most of the time?." Respondents used a 6-point scale from very happy to very unhappy to make a holistic appreciation of their subjective well-being. The variable was dichotomized as very unhappy to a bit happy (coded as 0) and happy to very happy (coded as 1) representing distinct levels of well-being. In the US version of ISRD-1, the question about happiness has shown to clearly make a distinction between average high school students and at-risk or incarcerated youth (Marshall et al., 2013). Also, life satisfaction has been linked with optimal mental health among adolescents (Park, 2004) and was used as a positive indicator of adjustment.

\section{Covariates}

Adolescents reported their age and gender, and socioeconomic status (SES) was measured through a summative index of eight items encompassing structural family variables and subjective affluence. Items were dichotomized as: single parent/other (0), nuclear family (1)/; father unemployed (0), employed (1); mother unemployed (0), employed (1); non-work income (0), work or capital income (1); welfare recipients (0), non-recipients (1); minority status (0), non-minority (1); subjective family and personal affluence in 7-point scales, much worse to the same (0), a little better to much better (1).

\section{Statistical analyses}

Descriptive statistics were used to examine adolescent outcomes and the type and frequency of after-school activity involvement. Next, patterns of after-school time use were analyzed using cluster analysis. On a person-centered approach to data, cluster analysis is an emerging statistical analysis technique used for identifying groups of individuals that are analogous across variables of interest. In this study, a cluster represents a group of adolescents that spent their leisure in a similar time use pattern. Based on their similarity, each cluster represents a group of adolescents as similar as possible with each other in terms of the frequency of activities (within-group homogeneity) but as different as possible to the remaining clusters (between-group heterogeneity) (Clatworthy et al., 2005). The cluster analysis with the time use variables (sports, study, creative, social 1 , social 2, shared family meals, evenings out) was conducted in three steps: a hierarchical procedure (Ward's method), followed by an iterative nonhierarchical method (K-means), and finally, the validation of the cluster solution (see Supplementary Appendix 1). As a result, each participant was assigned a specific cluster membership. Then, descriptive statistics and Chi-square tests (with column proportion $z$-tests) were employed to examine age, gender and SES differences in activities and time use patterns (clusters) of adolescents. To study the associations between time use patterns and adolescent adjustment, logistic regression models were employed, and odds-ratios and 95\% confidence intervals were calculated. The main effects of cluster membership (predictors) on dependent variables were analyzed in Model 1. Those effects were then assessed adjusting for the covariates of age, gender, and SES in Model 2. To detect subgroup variations in the previous model, interaction terms were added in separate analysis for each of the covariates in Model 3 (age/gender/SES $\times$ cluster membership). Both model and step fit 
Table 1. Sample description of time use activities.

\begin{tabular}{lcccc}
\hline Activities & Frequently & Sometimes & Never & $n$ \\
\hline Sports & $44.7 \%$ & $37.8 \%$ & $17.6 \%$ & 3,796 \\
Study & $36.2 \%$ & $51.1 \%$ & $12.7 \%$ & 3,786 \\
Creative & $19.3 \%$ & $36.2 \%$ & $44.5 \%$ & 3,787 \\
Social 1 $^{\text {a }}$ & $13.6 \%$ & $52.8 \%$ & $33.6 \%$ & 3,786 \\
Social 2 & $31.0 \%$ & $53.4 \%$ & $15.6 \%$ & 3,786 \\
Family meals per week & $6-7$ meals 86.1\% & $4-5$ meals 4.7\% & $0-3$ meals 9.2\% & 3,791 \\
Evenings out per week & 2-7 evenings 29.9\% & 1 evening 37.3\% & 0 evenings 32.7\% & 3,690 \\
\hline
\end{tabular}

Note. ${ }^{a}$ cafes, bars or concerts; ${ }^{b}$ shopping centers, streets, parks, neighborhoods.

statistics of the logistic regressions are reported representing the predictive power added by each model and by each step. All statistical analyses were conducted with IBM SPSS (Version 24).

\section{Results}

Regarding adolescent outcomes, 37\% of the adolescents in our sample reported that their grades were between above average to excellent, $51 \%$ average, and $13 \%$ weak to below average. In terms of past-year offending, 31\% were involved at least in one offense. A significant portion of adolescents (27\%) also reported at least one episode of binge drinking in the previous month, and a smaller proportion (7\%) reported at least one episode of cannabis smoking. Sixty-six percent reported having felt mostly happy or very happy in the previous six months, comparatively with the remaining $34 \%$ that reported feeling from very unhappy to a bit happy.

\section{After-school leisure activities and time use patterns by age, gender, and SES}

The first research question was: Does the way adolescents spend their after-school leisure time, in terms of both discrete categories of activities and patterns of time use, vary according to age, gender, and SES? The frequency of after-school leisure activity participation and adolescent time use patterns were examined (see Table 1). Adolescents frequently spent their leisure time in sports and study activities, as well as in social contexts such as shopping centers, streets or parks. Less time was devoted to creative activities, essentially theater, music, or reading, and unsupervised social contexts like cafes, bars or concerts. The vast majority reported having daily meals with parents and about two-thirds went out in the evening at least once every week. In addition, the participation of adolescents by age, gender, and SES was analyzed (see Table 2). Younger adolescents (12-15 years) reported a higher involvement with sports, study and creative activities, as well as a higher number of family meals per week. Conversely, older adolescents (16-18 years) reported being more frequently involved with social activities and evenings out. Also, girls reported being more frequently involved with studying, creative and social activities than boys, and less involved with sports and evenings out. In addition, a higher SES was associated with a higher involvement with sports and study activities, as well as a higher number of family meals per week.

A cluster analysis was conducted in order to identify the after-school time use patterns of adolescents (for a full description of the cluster analysis procedures and solution see Supplementary Appendix 1 and Figure 1, respectively). The five clusters that 


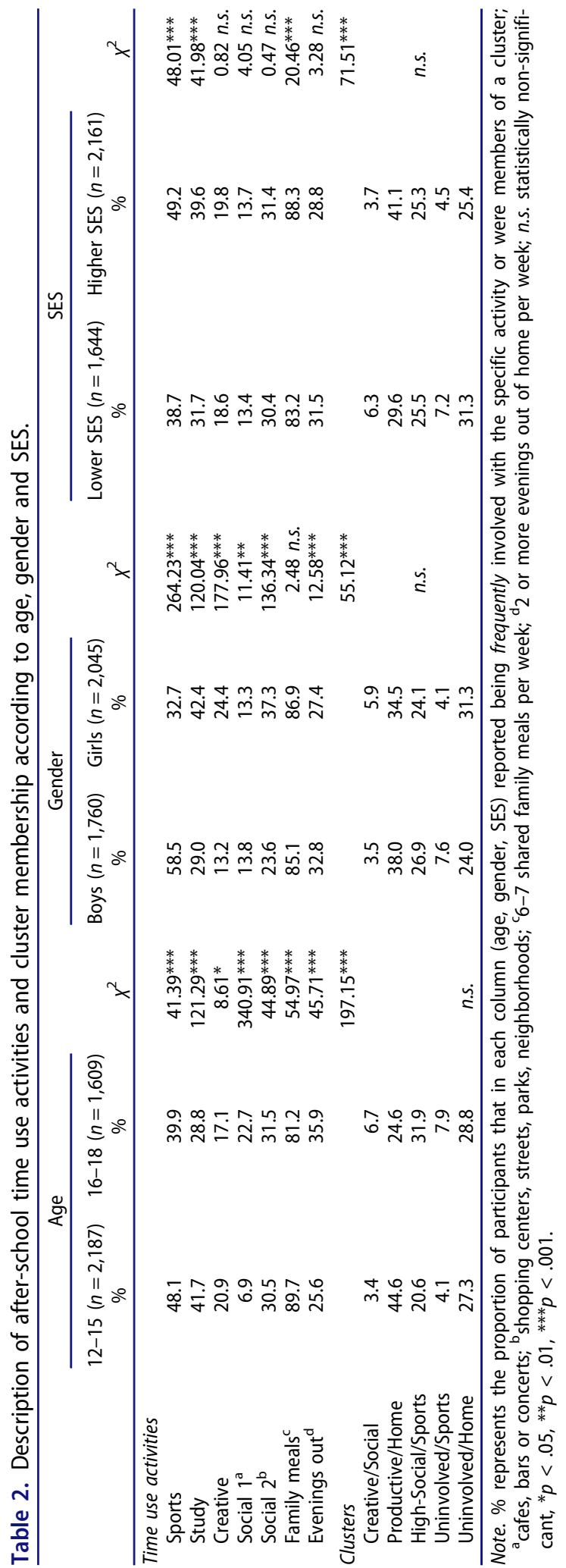




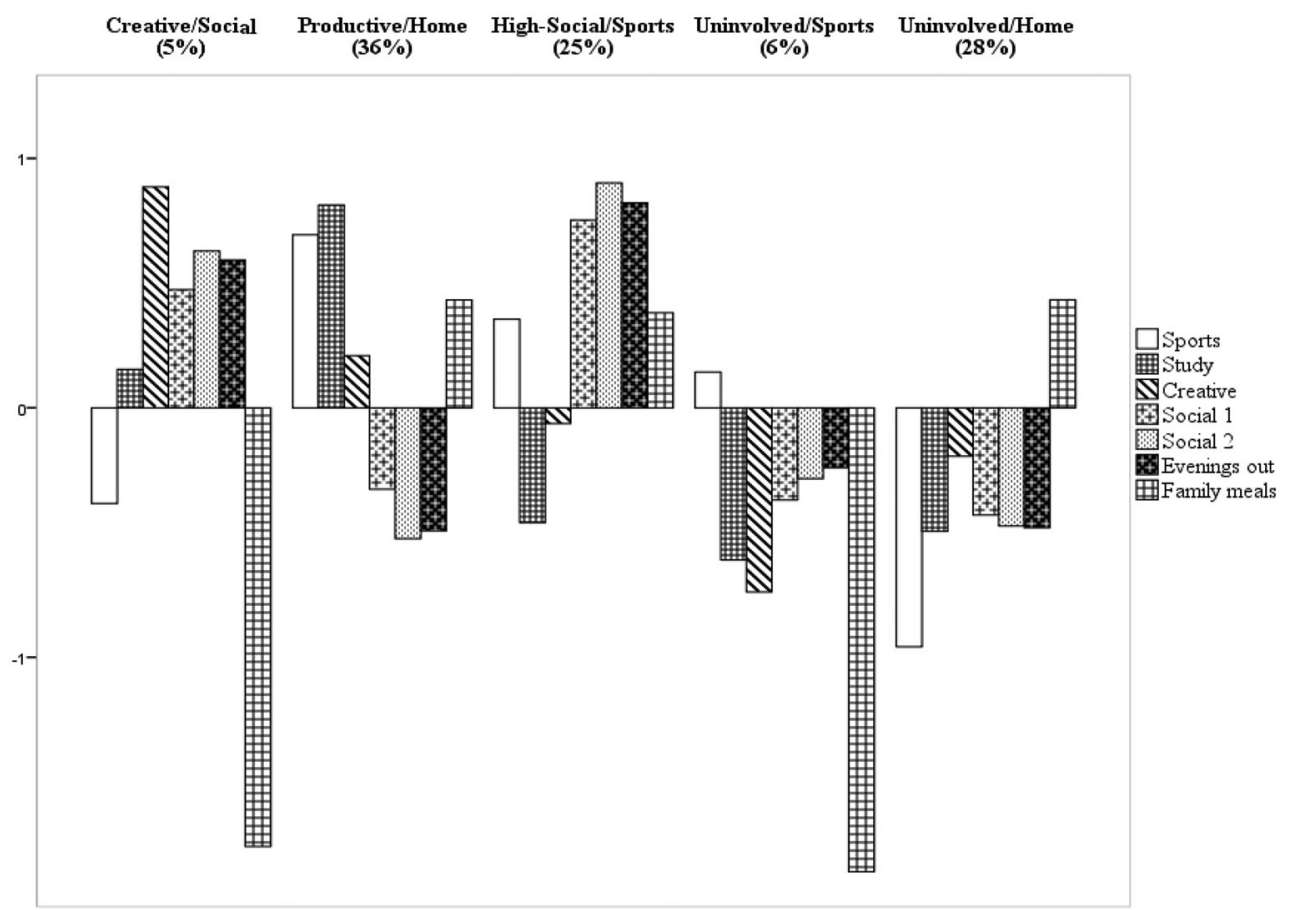

Figure 1. Standardized after-school activities for the five-cluster solution.

emerged were classified according to cluster-specific values as well as the patterns of cooccurring behaviors reported by adolescents (see Ferrar et al., 2013). The first cluster was characterized by a high involvement in creative and social activities as well as evenings out, average studying levels, and a very low level of shared family meals. This cluster was termed Creative/Social $(n=183 ; 5 \%)$. Adolescents in the second cluster were engaged primarily in sports, study and creative activities as well as family meals, and had low engagement with social activities and evenings out, thus being labeled Productive/Home $(n=1,375 ; 36 \%)$. The third cluster was characterized by the highest involvement in social activities and evenings out, as well as with sports and family meals, but presented a lower involvement with study and creative activities. This cluster was labeled High-Social/Sports $(n=966 ; 25 \%)$. The fourth cluster was engaged in sports on an average level but was disengaged from all remaining activities, including a very low participation in family meals, thus being termed Uninvolved/Sports $(n=217 ; 6 \%)$. The fifth cluster, similar to the previous cluster, was characterized by an overall very low engagement with activities except for family meals and was labeled Uninvolved/ Home $(n=1,064 ; 28 \%)$. As a cluster validation procedure, we assessed if the companionship in leisure time was associated with the cluster membership in a meaningful way $\left[\chi^{2}(8)=255.96, p<.001\right]$. As expected, the clusters High-Social/Sports, Creative/ Social, and Uninvolved/Sports were mostly composed of adolescents involved with peers in their leisure time, whilst the largest proportions of leisure time spent in the family context were found in the clusters Productive/Home and Uninvolved/Home.

Age, gender, and SES differences were analyzed in relation to cluster membership (see Table 2). Both age groups were similarly represented in the Uninvolved/Home 


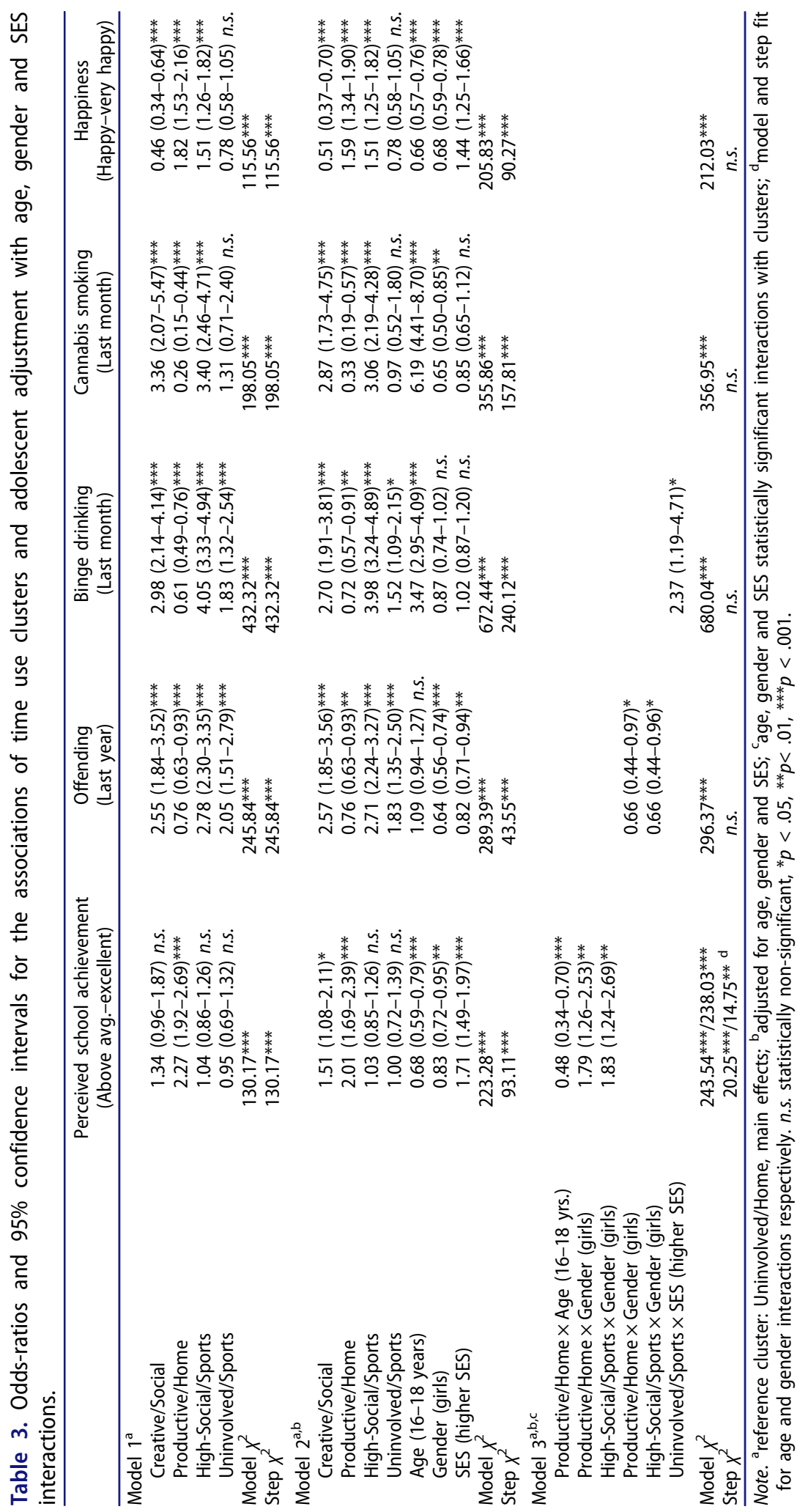


cluster, but younger adolescents tended to be represented in higher numbers in the Productive/Home cluster whilst their older counterparts were more likely to be in the High-Social/Sports, the Creative/Social, and the Uninvolved/Sports clusters. Girls were in higher numbers in the Creative/Social and Uninvolved/Home clusters, whilst boys were overrepresented in the Uninvolved/Sports and the Productive/Home clusters. In addition, higher SES youth were overrepresented in the Productive/Home cluster whilst lower SES youth were present in a higher proportion in the Creative/Social, Uninvolved/Sports, and Uninvolved/Home clusters.

\section{Associations between patterns of time use and adolescent adjustment}

The second research question was: Are after-school patterns of time use associated with adolescent adjustment? Logistic regression models were tested and both odds-ratios and 95\% confidence intervals were displayed in Table 3 . The results show the associations of cluster membership, adolescent adjustment, and covariates using the Uninvolved/Home cluster as the reference group. In addition, statistically significant interactions with age, gender, and SES are described.

Time use patterns were linked to adolescent adjustment, even after controlling for the covariates (Table 3, Model 2). The Productive/Home cluster was associated with an overall better adjustment, with higher perceived school achievement and happiness, and a lower likelihood of being engaged in offending, binge drinking, and cannabis smoking. The High-Social/Sports cluster members were more likely to report higher levels of happiness but were also more likely to engage with offending, binge drinking, and cannabis smoking. The Creative/Social cluster members were more likely to report above average to excellent perceived school achievement but were less happy and were more likely to engage in offending, binge drinking, and cannabis smoking. Together with the HighSocial/Sports cluster, the Creative/Social cluster was associated with higher risks for adolescent adjustment. The Uninvolved/Sports cluster members were more likely to engage in offending and binge drinking and, comparatively, the Uninvolved/Home cluster (reference group) showed a lower likelihood of behavioral problems but also a lower likelihood of achievement and happiness.

\section{Associations between patterns of time use and adolescent adjustment according to age, gender, and SES}

The third research question was: Do the associations between patterns of time use and adolescent adjustment vary according to age, gender, and SES? Sociodemographic differences were found in relation to adolescent adjustment. Higher levels of problem behaviors and lower perceived school achievement and happiness were found for older adolescents, boys, as well as lower SES youth. However, gender was not associated with binge drinking episodes in the last month and SES was not associated with episodes of binge drinking and cannabis smoking (see Table 3, Model 2). Subsequently, statistically significant interactions between patterns of time use and age, gender and SES were found (see Table 3, Model 3). Members of the Productive/Home cluster were more likely to report above average to excellent perceived school achievement, particularly 
girls, but not older adolescents. Moreover, girls in the High-Social/Sports cluster were more likely to report higher levels of perceived school achievement than boys. In addition, girls in the Productive/Home and High-Social/Sports clusters were also less likely to engage in offending (higher risk for boys). Finally, higher SES adolescents in the Uninvolved/Sports clusters were more likely to engage in binge drinking.

\section{Discussion}

This study aimed at examining the after-school time use of 7 th-12th graders and its links with adjustment, contributing to a better understanding of the well-being effects of leisure time in adolescence. We measured adolescent participation in leisure activities and assessed the patterns of after-school time. Overall, it was observed that time use meaningfully varied by age, gender, and SES, and that time use patterns significantly influenced adolescent adjustment, with substantial subgroup variations. To our knowledge, very few studies in the European context have addressed adolescent after-school portfolios of activities and adjustment. In addition, by using a person-centered approach, we were able to describe different patterns of after-school time use. Activity choices and participation opportunities clustered differently across the population not corresponding to a zero-sum model of leisure (Shanahan \& Flaherty, 2001). Clusters were indeed multidimensional and organized in distinct patterns (e.g., academic-oriented, socially oriented, low-engagement), and varied by the breadth of activity involvement (e.g., uninvolved, single activity, and involved in multiple activities) (see Ferrar et al., 2013).

Our first research question was related to the analysis of the way adolescents spend their after-school leisure time, in terms of both discrete categories of activities as well as patterns of time use, and how these vary according to age, gender, and SES. Generally, our findings are similar to previous research that has reported an increase in time spent in social activities across the adolescent years, as well as a lower investment of girls in physical activities and evenings out in opposition to a higher involvement with academic pursuits, reading, and shopping when compared with boys. In addition, adolescents from higher SES families were found to be more engaged with sports, study, and family meals, in comparison to lower SES adolescents (Barnes et al., 2007; Bartko \& Eccles, 2003; Currie et al., 2012; Hunt et al., 2014; Inchley et al., 2016; Olds et al., 2009; Pedersen, 2005).

Our analysis of adolescent time use patterns provided a better understanding of the distribution of activities across different groups of the population. A higher proportion of younger adolescents were in the Productive/Home cluster, whilst older adolescents were either in the socially oriented or disengaged clusters. This change is probably associated with a specialization effect that our study design was unable to detect (Denault \& Poulin, 2009). In addition, it is recognized that greater autonomy-seeking from youths and autonomy-granting from parents, as adolescents grow older and seek for new roles and experiences with peers, is a key developmental process that explains such age differences (Larson et al., 1996; Millstein et al., 1994). Unlike previous research, boys and girls were almost equally represented in the highly engaged clusters (i.e., Productive/ Home, High-Social/Sports). Conversely, gender differences were more evident in the 
disengaged patterns: boys were in the sports and uninvolved cluster and girls in the home and uninvolved cluster (Bartko \& Eccles, 2003; Feldman \& Matjasko, 2007; Linver et al., 2009; Shanahan \& Flaherty, 2001; Wolf et al., 2015). In addition, adolescents from less affluent families were less participative (i.e., higher representation in the disengaged clusters), whilst higher SES adolescents were represented in the academic-oriented and highly engaged clusters, also observed in previous literature (Linver et al., 2009; Pedersen, 2005).

These findings contribute to a better comprehension of the factors influencing adolescents' time use patterns. As Denault and Poulin (2009) suggest, schools and community-based organizations aiming at involving adolescents in positive, enriching activities in their leisure time should target individual, peer and family characteristics, as well as consider the affordances and constraints present in youths developmental settings. Family and community resources, youth characteristics and parents' attributions associated with leisure and development, as well as the nature of activities, may influence the quantity and quality of after-school opportunities offered to adolescents. This may result in different arrangements of leisure time for different groups of the population with implications for well-being and growth (Lam \& McHale, 2015). Indeed, long-term implications of these activity patterns are significant for youth development, since students involved with multiple activities are likely to remain so across several grades (Denault \& Poulin, 2009; Shanahan \& Flaherty, 2001).

Our second research question was related to the investigation of how after-school patterns of time use are associated with adolescent adjustment. Our findings indicate that adolescents engaged in a higher number of constructive activities (e.g., family time; cognitive, academic, sports-oriented activities) presented better adjustment compared with their single-activity or uninvolved counterparts, and that disengaged or unstructured patterns of time use may constitute a context for risk (Bartko \& Eccles, 2003; Wolf et al., 2015). For example, the Productive/Home cluster was associated with an overall better adjustment, conversely, the High-Social/Sports and Creative/Social clusters were linked to higher risks of adjustment (Badura et al., 2016; Himelfarb et al., 2014). The Uninvolved/Sports cluster was also associated with some risks to adjustment with a higher likelihood of problem behaviors. Comparatively, the Uninvolved/Home cluster was associated with lower risks for problem behaviors, still presented lower levels of achievement and happiness.

These findings indicate that adolescent outcomes are meaningfully linked with unique combinations of time use. One advantage of this fine-grained view is that it goes beyond the analysis of the effects of single categories of activities or the breadth of involvement (Metzger et al., 2009). They are also consistent with prior findings that participation in multiple, structured, productive, and complementing activities is linked with optimal psychosocial adjustment and positive youth development (Agans et al., 2014; Bartko \& Eccles, 2003; Forneris et al., 2015; Rose-Krasnor et al., 2006). Metzger et al. (2009) found six patterns of time use differentially associated with delinquency, negative affect and GPA, with higher risks observed for the uninvolved, community and sports, and school and community groups, and better adjustment for the multiply involved group. Similarly, Linver et al. (2009) found five activity clusters, in which youths who participated in sports plus other activities showed better developmental 
outcomes compared with those with little or no involvement and those who participated only in sports.

Usually, a more structured use of time and the participation in goal-oriented activities developed in schools or in the community provides increased opportunities to learn new skills and healthy behaviors, form a social support network with prosocial peers and adults, and develop a positive identity and a sense of self-efficacy (Forneris et al., 2015; Lam \& McHale, 2015). Differences in time use choices have an impact on adolescent adjustment and may help explain developmental gaps among different social groups. Particularly when considering the protective effects of time spent with the family and the importance of activities developed at home or with parents that may provide complementing growth experiences (Lam \& McHale, 2015; Larson et al., 1996). Across adolescence, young people begin to individuate from their parents, experiencing increased pulls from outside the home and seeking for autonomy (Larson et al., 1996; Millstein et al., 1994). Investment in experiences with peers in new social contexts could happen at the expense of family, academic and organized activities. Augmented time spent with peers in unstructured social activities and lower interactions with family members have been associated with risk behaviors and lower achievement, especially for boys, as health-compromising behaviors increase (Barnes et al., 2007; Currie et al., 2012; Giorgi, 2014; Mahoney et al., 2004; Mancini \& Huebner, 2004). Despite the changes in family dynamics that occur throughout adolescence and the multiple challenges that youth face, family time and shared activities can constitute a context for the development of a positive identity, for bonding with supporting adults and siblings, for creating a compass for healthier choices, as well as for the development of problem-solving skills and positive future expectations (Larson et al., 1996; Mancini \& Huebner, 2004; Millstein et al., 1994). The results reported in the present study can inform families, communities and services that aim at effectively enhancing the health and development of adolescents.

Our third research question was related to the expectation that the associations between patterns of time use and adolescent adjustment would vary according to age, gender, and SES. This was an important addition of the present study as we observed subgroup variations on adolescent adjustment. We found that a more socially oriented or unstructured use of time constituted a context for higher behavioral risk, specifically for groups of older adolescents, boys, as well as lower SES youth. Interaction effects in population subgroups are needed in time use studies for a more nuanced interpretation of the developmental effects of leisure as well as to guide intervention strategies. For example, membership in the Productive/Home cluster was positively associated with achievement, with a stronger association for girls, but not for older adolescents. Moreover, girls in the Productive/Home cluster were less likely to be involved in offending when compared with boys. Notably, the High-Social/Sports cluster was not associated with achievement and was linked to a higher probability of offending in boys, while girls showed significantly higher achievement and lower odds of offending.

These findings indicate that, overall, girls benefited more than boys from membership in the two highly engaged clusters, and that similar patterns of time use can have gendered effects for youth. Activities can be developmentally protective depending on the quality and structure of the settings where they ensue, the combined types of activities 
(e.g., sports, studying, family time), as well as the behavior of peers and adults involved. Boys and girls may seek specific activities and settings that reflect their maturity level and individual attributes, that make them feel more comfortable, to which they have greater competence beliefs and feel more motivated to participate, or to which they may have received parental guidance. Also, from a young age, boys and girls show gendered expectations toward everyday activities and the social contexts where they ensue, being more prone to gender-typed socialization and thus self-selecting into varying activities (Denault \& Poulin, 2009). In addition, almost no SES subgroup variations were observed suggesting a more important role for SES as a selection variable in activity participation. To our knowledge, few studies have analyzed variations in the relationship between multidimensional patterns of leisure activities and the adjustment of adolescents across sociodemographic groups. Future research should include the analysis of the role of parenting practices (e.g., parental supervision/monitoring, autonomy-granting) and family cultural orientations, which shape the socialization experiences of youths, and may self-select youth into different activity participation profiles as a function of age, gender and SES.

Finally, in terms of adolescent outcomes, our findings indicate the existence of several issues related to adolescent health behaviors. Portugal decriminalized the acquisition and possession of drugs for personal consumption and has established two legal drinking ages for different alcoholic drinks (16 years for wine and beer and 18 years for all alcoholic beverages). The prevalence of problem behaviors considered herein are in line with recent literature (Enzmann et al., 2018; Giorgi, 2014; Kraus \& Nociar, 2016). However, an upwards trend, specifically the binge-drinking outcome, might be related to the age interval of our sample (up to 18 years) compared with other studies, but also with an urban youth culture associated with heavy-drinking and cannabis smoking with peers in social contexts (e.g., nights out). Also, about a third of the adolescents reported lower levels of experienced happiness in the previous six months suggesting possible psychological difficulties, a public health challenge regarding youth still unmet and in need of further intervention (Patel et al., 2007). This indicates the existence of societal challenges in several domains of adjustment that warrant effective interventions aimed at enhancing adolescent well-being. It also brings to our attention the need of examining the role of after-school leisure as a relevant context for positive development and health promotion, of which organized activities and time with family are key developmental assets.

Several limitations of this study should be considered. The cross-sectional design and sample characteristics limit any causal inference and the generalization of results beyond urban youth in an EU context. In addition, time use variables employed in our analyses did not include the full spectrum of activities adolescents engage with (e.g., screen/media time, inactivity, work, self-maintenance, clubs), neither pre-adjustment variables were controlled for. Moreover, time use variables do not reflect the actual features of activity settings, the quality of the experiences, the level of individual engagement, nor the meaning of each activity. This limited our ability to fully examine and report the after-school time use of adolescents and improve the predictability of our models. 


\section{Conclusion}

The present study contributes to a more detailed understanding of the time use of adolescents and its links with adjustment in a southern European context, expanding the examination of after-school time use as a context for the promotion of adolescent wellbeing. To our knowledge, this is one of the few studies using person-centered analysis to examine the lives of adolescents in the European context. We documented that patterns of after-school time use were multidimensional and significantly associated with adolescent outcomes and, as expected, varied according to age, gender, and SES. Thus, our study highlights varying opportunities for different groups of adolescents with implications for growth and development. We also identified some needs concerning adolescents' behavioral health that warrant intervention at both the national and local levels. In addition, a large proportion of adolescents were either uninvolved or adhered to a more unsupervised/unstructured time use. After-school leisure is a context for health promotion, and youth, families and communities must be involved in shaping structured time use contexts that support adolescent development. Family-, school- and community-based activities could be considered as key assets in the promotion of adolescent well-being. Because we examined a sample that included pre-adolescents, adolescents, and young adults, these findings may inform practitioners, schools, services, and policymakers in the provision of effective opportunities for a more healthy and constructive use of time (e.g., community and school-based programs, family shared activities, organized activities), particularly in the case of underprivileged youth and at-risk boys and girls. Further investigation should include experimental and longitudinal designs aimed at testing the causal relationships between after-school time use and adolescent well-being, and understanding the mechanisms underlying positive effects on adolescent development.

\section{Disclosure statement}

All authors were involved with the conceptualization and manuscript writing. The authors declare that have no conflict of interests.

\section{Funding}

This work was supported by the Research Center in Political Science [UID/CPO/00758/2013], University of Minho, supported by the FCT (Foundation for Science and Technology) and the Portuguese Ministry of Education and Science through national funds, and by the Research Center on Child Studies [UID/CED/00317/2013], University of Minho, through national funds through the FCT, and co-financed by the European Regional Development Funds (FEDER) and the Competitiveness and Internationalization Operational Program (POCI), reference [POCI-010145-FEDER-007562].

\section{ORCID}

Paula Cristina Martins (D) http://orcid.org/0000-0002-0160-5066

Vitor Hugo Oliveira (DD http://orcid.org/0000-0002-1998-8579

Sílvia Maria Mendes (D) http://orcid.org/0000-0002-1644-5333 
Gloria Fernández-Pacheco (D) http://orcid.org/0000-0002-2193-3227

\section{References}

Agans, J. P., Champine, R. B., DeSouza, L. M., Mueller, M. K., Johnson, S. K., \& Lerner, R. M. (2014). Activity involvement as an ecological asset: Profiles of participation and youth outcomes. Journal of Youth and Adolescence, 43(6), 919-932. https://doi:10.1007/s10964-0140091-1

Badura, P., Geckova, A. M., Sigmundova, D., van Dijk, J. P., \& Reijneveld, S. A. (2015). When children play, they feel better: Organized activity participation and health in adolescents. $B M C$ Public Health, 15(1), 1-8. https://doi.org/10.1186/s12889-015-2427-5

Badura, P., Sigmund, E., Madarasova Geckova, A., Sigmundova, D., Sirucek, J., van Dijk, J. P., \& Reijneveld, S. A. (2016). Is participation in organized leisure-time activities associated with school performance in adolescence? PLoS One, 11(4), e0153276. https://doi.org/10.1371/journal.pone. 0153276

Barnes, G. M., Hoffman, J. H., Welte, J. W., Farrell, M. P., \& Dintcheff, B. A. (2007). Adolescents' time use: Effects on substance use, delinquency and sexual activity. Journal of Youth and Adolescence, 36(5), 697-710. https://doi.org/10.1007/s10964-006-9075-0

Bartko, W. T., \& Eccles, J. S. (2003). Adolescent participation in structured and unstructured activities: A person-oriented analysis. Journal of Youth and Adolescence, 32(4), 233-241. https://doi.org/10.1023/A:1023056425648

Caldwell, L. L., \& Smith, E. A. (2006). Leisure as a context for youth development and delinquency prevention. Australian \& New Zealand Journal of Criminology, 39(3), 398-418. https:// doi.org/10.1375/acri.39.3.398

Clatworthy, J., Buick, D., Hankins, M., Weinman, J., \& Horne, R. (2005). The use and reporting of cluster analysis in health psychology: A review. British Journal of Health Psychology, $10(\mathrm{Pt}$ 3), 329-358. https://doi.org/10.1348/135910705X25697

Covay, E., \& Carbonaro, W. (2010). After the bell: Participation in extracurricular activities, classroom behavior, and academic achievement. Sociology of Education, 83(1), 20-45. https://doi. org/10.1177/0038040709356565

Currie, C., Zanotti, C., Morgan, A., Currie, D., DeLooze, M., Roberts, C (2012). Barnekow, V. Social determinants of health and well-being among young people. Health behavior in school-aged children (HBCS) study: International report from the 2009/2010 survey. WHO. http:// www.euro.who.int

Darling, N. (2005). Participation in extracurricular activities and adolescent adjustment: Crosssectional and longitudinal findings. Journal of Youth and Adolescence, 34(5), 493-505. https:// doi.org/10.1007/s10964-005-7266-8

Denault, A. S., \& Poulin, F. (2009). Predictors of adolescent participation in organized activities: A five-year longitudinal study. Journal of Research on Adolescence, 19(2), 287-311. https://doi. org/10.1111/j.1532-7795.2009.00597.x

DuRant, R. H., Smith, J. A., \& Kreiter, S. R. (1999). The relationship between early age of onset of initial substance use and engaging in multiple health risk behaviors among young adolescents. Archives of Pediatrics and Adolescent Medicine, 153(3), 286-291. https://doi:10.1001/ archpedi.153.3.286

Eccles, J. S., Barber, B. L., Stone, M., \& Hunt, J. (2003). Extracurricular activities and adolescent development. Journal of Social Issues, 59(4), 865-889. https://doi.org/10.1046/j.0022-4537.2003. 00095.x

Enzmann, D., Kivivuori, J., Marshall, I. H., Steketee, M., Hough, M., \& Killias, M. (2018). A global perspective on young people as offenders and victims: First results from the ISRD3 Study (pp. 96). Springer Briefs in Criminology. https://doi:10.1007/978-3-319-63233-9

Farb, A. F., \& Matjasko, J. L. (2012). Recent advances in research on school-based extracurricular activities and adolescent development. Developmental Review, 32(1), 1-48. https://doi.org/10. 1016/j.dr.2011.10.001 
Feldman, A. F., \& Matjasko, J. L. (2005). The role of school-based extracurricular activities in adolescent development: A comprehensive review and future directions. Review of Educational Research, 75(2), 159-210. https://doi.org/10.3102/00346543075002159

Feldman, A. F., \& Matjasko, J. L. (2007). Profiles and portfolios of adolescent school-based extracurricular activity participation. Journal of Adolescence, 30(2), 313-332. https://doi.org/10.1016/ j.adolescence.2006.03.004

Ferrar, K., Chang, C., Li, M., \& Olds, T. S. (2013). Adolescent time use clusters: A systematic review. The Journal of Adolescent Health: Official Publication of the Society for Adolescent Medicine, 52(3), 259-270. https://doi:10.1016/j.jadohealth.2012.06.015

Forneris, T., Camiré, M., \& Williamson, R. (2015). Extracurricular activity participation and the acquisition of developmental assets: Differences between involved and noninvolved Canadian high school students. Applied Developmental Science, 19(1), 47-55. https://doi.org/10.1080/ 10888691.2014.980580

Fredricks, J. A., \& Eccles, J. S. (2006). Is extracurricular participation associated with beneficial outcomes? Concurrent and longitudinal relations. Developmental Psychology, 42(4), 698-713. https://doi:10.1037/0012-1649.42.4.698

Fredricks, J. A., \& Eccles, J. S. (2008). Participation in extracurricular activities in the middle school years: Are there developmental benefits for African American and European American youth? Journal of Youth and Adolescence, 37(9), 1029-1043. https://doi.org/10.1007/s10964008-9309-4

Fredricks, J. A., \& Eccles, J. S. (2010). Breadth of extracurricular participation and adolescent adjustment among African-American and European-American Youth. Journal of Research on Adolescence: The Official Journal of the Society for Research on Adolescence, 20(2), 307-333. https://doi:10.1111/j.1532-7795.2009.00627.x

Giorgi, M. (2014). Structured and unstructured activities and teenager crime: Data analysis of ISRD-2. Justicia Juris, 8(2), 11-26. https://doi.org/10.15665/rj.v8i2.167

Himelfarb, I., Lac, A., \& Baharav, H. (2014). Examining school-related delinquencies, extracurricular activities, and grades in adolescents. Educational Studies, 40(1), 81-97. https://doi.org/10. 1080/03055698.2013.821941

Hunt, E., \& McKay, E. A. (2015). What can be learned from adolescent time diary research. The Journal of Adolescent Health: Official Publication of the Society for Adolescent Medicine, 56(3), 259-266. https://doi.org/10.1016/j.jadohealth.2014.11.007

Hunt, E., McKay, E., Fitzgerald, A., \& Perry, I. (2014). Time use and daily activities of late adolescents in contemporary Ireland. Journal of Occupational Science, 21(1), 42-64. https://doi.org/ 10.1080/14427591.2013.867560

Inchley, J., Currie, D., Young, T., Samdal, O., Torsheim, T., Augustson, L (2016). Barnekow, V. Growing up unequal: gender and socioeconomic differences in young people's health and wellbeing. Health Behavior in School-aged Children (HBSC) study: International report from the 2013/2014 survey. WHO. http://www.euro.who.int

Kraus, L., Nociar, A. (2016). ESPAD report 2015: Results from the ESPAD survey. ESPAD. http:// www.espad.org/sites/espad.org/files/ESPAD_report_2015.pdf

Kristjánsson, A. L., Sigfúsdóttir, I. D., Allegrante, J. P., \& Helgason, A. R. (2009). Adolescent health behavior, contentment in school, and academic achievement. American Journal of Health Behavior, 33(1), 69-79. https://doi:10.5993/AJHB.33.1.7

Lam, C. B., \& McHale, S. M. (2015). Time use as cause and consequence of youth development. Child Development Perspectives, 9(1), 20-25. https://doi.org/10.1111/cdep.12100

Larson, R. W., \& Verma, S. (1999). How children and adolescents spend time across the world: Work, play, and developmental opportunities. Psychological Bulletin, 125(6), 701-736. https:// doi:10.1037/0033-2909.125.6.701

Larson, R. W., Richards, M. H., Moneta, G., Holmbeck, G., \& Duckett, E. (1996). Changes in adolescents' daily interactions with their families from ages 10 to 18: Disengagement and transformation. Developmental Psychology, 32(4), 744-754. https://doi.org/10.1037/0012-1649.32.4. 744 
Levin, K. A., Kirby, J., \& Currie, C. (2012). Adolescent risk behaviours and mealtime routines: does family meal frequency alter the association between family structure and risk behaviour? Health Education Research, 27(1), 24-35. https://doi:10.1093/her/cyr084

Linver, M. R., Roth, J. L., \& Brooks-Gunn, J. (2009). Patterns of adolescents' participation in organized activities: are sports best when combined with other activities? Developmental Psychology, 45(2), 354-367. https://doi:10.1037/a0014133

Loeber, R., Stouthamer-Loeber, M., \& White, H. R. (1999). Developmental aspects of delinquency and internalizing problems and their association with persistent juvenile substance use between ages 7 and 18. Journal of Clinical Child Psychology, 28(3), 322-332. https://doi:10.1207/ S15374424jccp280304

Mahoney, J. L., \& Stattin, H. (2000). Leisure activities and adolescent antisocial behavior: The role of structure and social context. Journal of Adolescence, 23(2), 113-127. https://doi:10. 1006/jado.2000.0302

Mahoney, J. L., Stattin, H., \& Lord, H. (2004). Unstructured youth recreation centre participation and antisocial behavior development: Selection influences and the moderating role of antisocial peers. International Journal of Behavioral Development, 28(6), 553-560. https://doi.org/10.1080/ 01650250444000270

Mancini, J. A., \& Huebner, A. J. (2004). Adolescent risk behavior patterns: Effects of structured time-use, interpersonal connections, self-system characteristics, and socio-demographic influences. Child and Adolescent Social Work Journal, 21(6), 647-668. https://doi.org/10.1007/s10560004-6409-1

Marshall, I. H., Enzmann, D., Hough, M., Killias, M., Kivivuori, J., \& Steketee, M. (2013). International Self-Report Delinquency Questionnaire 3 (ISRD-3): Background paper to explain ISRD2-ISRD3 changes (Vol. 1, pp. 139-157). ISRD3 Technical Report Series.

Metzger, A., Crean, H. F., \& Forbes-Jones, E. L. (2009). Patterns of organized activity participation in urban, early adolescents: Associations with academic achievement, problem behaviors, and perceived adult support. The Journal of Early Adolescence, 29(3), 426-442. https://doi.org/ $10.1177 / 0272431608322949$

Millstein, S. G., Petersen, A. C., \& Nightingale, E. O. (Eds.). (1994). Promoting the health of adolescents: New directions for the twenty-first century. Oxford University Press.

Olds, T., Wake, M., Patton, G., Ridley, K., Waters, E., Williams, J., \& Hesketh, K. (2009). How do school-day activity patterns differ with age and gender across adolescence? The Journal of Adolescent Health: Official Publication of the Society for Adolescent Medicine, 44(1), 64-72. https://doi.org/10.1016/j.jadohealth.2008.05.003

Park, N. (2004). The role of subjective well-being in positive youth development. The Annals of the American Academy of Political and Social Science, 591(1), 25-39. https://doi.org/10.1177/ 0002716203260078

Patel, V., Flisher, A. J., Hetrick, S., \& McGorry, P. (2007). Mental health of young people: A global public-health challenge. The Lancet, 369(9569), 1302-1313. https://doi.org/10.1016/S01406736(07)60368-7

Pedersen, S. (2005). Urban adolescents' out-of-school activity profiles: Associations with youth, family, and school transition characteristics. Applied Developmental Science, 9(2), 107-124. https://doi.org/10.1207/s1532480xads0902_5

Rose-Krasnor, L., Busseri, M. A., Willoughby, T., \& Chalmers, H. (2006). Breadth and intensity of youth activity involvement as contexts for positive development. Journal of Youth and Adolescence, 35(3), 365-399. https://doi.org/10.1007/s10964-006-9037-6

Shanahan, M. J., \& Flaherty, B. P. (2001). Dynamic patterns of time use in adolescence. Child Development, 72(2), 385-401. https://doi:10.1111/1467-8624.00285

Trainor, S., Delfabbro, P., Anderson, S., \& Winefield, A. (2010). Leisure activities and adolescent psychological well-being. Journal of Adolescence, 33(1), 173-186. https://doi:10.1016/j.adolescence.2009.03.013

Witkow, M. R. (2009). Academic achievement and adolescents' daily time use in the social and academic domains. Journal of Research on Adolescence, 19(1), 151-172. https://doi.org/10.1111/ j.1532-7795.2009.00587.x 
Wolf, S., Aber, J. L., \& Morris, P. A. (2015). Patterns of time use among low-income urban minority adolescents and associations with academic outcomes and problem behaviors. Journal of Youth and Adolescence, 44(6), 1208-1225. https://doi.org/10.1007/s10964015-0294-0 